\section{Functional Assessment Multiple} Sclerosis

Victor R. Preedy

Faculty of Life Sciences \& Medicine, King's

College London, London, UK

Synonyms

FAMS

\section{Definition}

A disease-specific self-report questionnaire that investigates six primary aspects of quality of life in patients with multiple sclerosis: mobility, symptoms, emotional well-being, general contentment, thinking/fatigue, and family/social well-being. Five of the six subcategories (mobility, symptoms, emotional well-being, general contentment, and family/social well-being) comprise seven items (score range: 0-28); the subcategory thinking/fatigue comprises nine items (score range: 0-36).

\section{Cross-References}

- Multiple Sclerosis

- Multiple Sclerosis Quality of Life-54 Questionnaire

\section{References and Readings}

Preedy, V. R., \& Watson, R. R. (Eds.). (2010). Handbook of disease burdens and quality of life measures (Vol. 6, p. 4211). New York: Springer. 